University of Nebraska - Lincoln

DigitalCommons@University of Nebraska - Lincoln

Hendricks Symposium--Department of Political

Science

Political Science, Department of

October 2006

\title{
Effects of "In-Your-Face" Television Discourse on Perceptions of a Legitimate Opposition
}

Diana C. Mutz

University of Pennsylvania

Follow this and additional works at: https://digitalcommons.unl.edu/politicalsciencehendricks

Part of the Political Science Commons

Mutz, Diana C., "Effects of "In-Your-Face" Television Discourse on Perceptions of a Legitimate Opposition" (2006). Hendricks Symposium--Department of Political Science. 16.

https://digitalcommons.unl.edu/politicalsciencehendricks/16

This Article is brought to you for free and open access by the Political Science, Department of at DigitalCommons@University of Nebraska - Lincoln. It has been accepted for inclusion in Hendricks Symposium-Department of Political Science by an authorized administrator of DigitalCommons@University of Nebraska - Lincoln. 


\title{
Effects of "In-Your-Face" Television Discourse on Perceptions of a Legitimate Opposition
}

\author{
Diana C. Mutz \\ Samuel A. Stouffer Professor of Political Science and Communication \\ 3620 Walnut Street \\ Philadelphia, PA 19104 \\ Email: mutz@sas.upenn.edu
}

This research was supported by a grant from the National Science Foundation. The author would like to thank R. Andrew Holbrook and Shiloh Krieger for their help with data collection, and special thanks are due to Byron Reeves for his help with the collection and analysis of physiological data. 


\title{
Effects of "In-Your-Face" Television Discourse on Perceptions of a Legitimate Opposition
}

\begin{abstract}
How do Americans acquire the impression that their political foes have some understandable basis for their views, and thus represent a legitimate opposition? How do they come to believe that reasonable people may disagree on any given political controversy? Given that few people talk regularly to those of opposing perspectives, some theorize that mass media, and television in particular, serve as an important source of exposure to the rationales for oppositional views. A series of experimental studies suggests that television does, indeed, have the capacity to encourage greater awareness of oppositional perspectives. However, common characteristics of televised political discourse cause audiences to view oppositional issue perspectives as less legitimate than they would have otherwise. I discuss the broader implications of these findings for assessments of the impact of television on the political process, and for the role that televised political discourse may play in encouraging polarized political views.
\end{abstract}




\title{
Effects of "In-Your-Face" Television Discourse on Perceptions of a Legitimate Opposition
}

\begin{abstract}
"Do we truly believe that ALL red-state residents are ignorant racist fascist knuckledragging NASCAR-obsessed cousin-marrying road-kill-eating tobacco-juice-dribbling gun-fondling religious fanatic rednecks; or that ALL blue-state residents are godless unpatriotic pierced-nose Volvo-driving France-loving left-wing Communist latte-sucking tofu-chomping holistic-wacko neurotic vegan weenie perverts?"

--Dave Barry, December 18, 2004
\end{abstract}

Conflict is central to democracy. The legitimacy of democratic outcomes requires that political options be contested. And yet it also rests on the premise that each side in any given controversy perceives the opposition as having some reasonable foundation for its positions. When citizens end up on the losing side in any given contest, whether of policy positions or candidates, ideally they should perceive the opposition as having some basis for its positions, however mistaken, shortsighted, or benighted that perspective might seem.

Given that few people speak directly to political advocates of opposing views, how do Americans come to perceive that reasonable people may disagree on any given political controversy? Some theorize that mass media, and television in particular, serve this purpose most regularly in the United States (Calhoun 1988; Page 1996). Political discourse that reaches citizens through television is widely believed to be the major means by which citizens learn the rationales for opposing perspectives. The central questions motivating this study are: 1) Does televised political discourse familiarize viewers with rationales for oppositional political perspectives? and 2) If so, does it thereby enhance the extent to which oppositional views are perceived as legitimate? Secondarily, this study also sheds light on a broader, more intransigent question that has plagued the study of media and politics since 
the advent of television: What difference does it make that most of what people experience of public discourse in the political world reaches them through television?

\section{THE FUNCTIONS OF PUBLIC DISCOURSE}

Few question that the quality of public discourse on matters of political controversy is important. But the typical reasons for concern generally involve the extent to which the public becomes well informed as a result of exposure to public discourse, or the extent to which it is able to form rational opinions about candidates and policies as a result. This study focuses instead on how citizens feel about the "other side," that is, the candidate or policy position that is not their preferred option. Although this outcome is far less studied than how citizens form preferences, it is arguably of equal importance to the stability of a political system. Without the acquiescence of those on the losing side, democratic government could not continue peaceably. And without some degree of respect for oppositional views, it is doubtful that the losers in any given contest would tolerate the winners for long. Although some might argue that it is respect for the process, not for oppositional perspectives, that compels those on the losing side to continue, a process that produces outcomes that seem totally without justification is unlikely to persist.

Normative political theory has long been convinced of the importance of respect for oppositional views. For example, deliberation is so strongly advocated in part because it requires that reason-giving occur among those of diverse views, with the ultimate goal that individuals come to respect and appreciate those with views unlike their own (Benhabib 1992, Arendt 1968). Public deliberation is assumed to promote greater awareness of both oppositional views and their justifications (Manin 1987). By making public the rationales behind opposing sides of a controversy, the losers in a given controversy come to know the reasons or arguments the winners judged to be stronger: "Hence discussion rather than 
private deliberation would be necessary to 'put on the table' the various reasons and arguments that different individuals had in mind, and thus to ensure that no one could see the end result as arbitrary rather than reasonable and justifiable, even if not what he or she happened to see as most justifiable" (Fearon 1998: 62).

Some recent studies of electoral behavior suggest that being on the losing side in any given contest has consequences for the way citizens feel about their political system. In research on what they term "loser's consent," Anderson and colleagues (2005) demonstrate that beyond the understandable initial disappointment suffered by losers, there are also effects on system-level attitudes that persist and accumulate over long periods of time, leading to diminished support for democratic principles, and to greater support for institutional change. To maintain democratic stability, it is therefore important to understand not only who wins and why people supported a given candidate, but also why those on the losing side accept the decision to the point that they are willing to be governed by this person or policy.

Because of the strong traditional focus in election research on explaining preferences, empirical studies of people's attitudes toward the opposition are limited. However, as scholars have become increasingly concerned over the last decade about potential polarization within the American electorate, more attention has been focused on how much citizens despise the opposition, as well as how much they like their own candidate or party. At present, there is far more consensus on the existence of polarization among political elites than among the mass public (e.g., Fiorina 2004; Fleisher and Bond 2004) Nonetheless, some evidence is consistent with this thesis, and suggestive of less respect for oppositional views. For example, at least since the Eisenhower administration, the gap between Republican and Democratic citizens' approval of the president has never been as wide as it has become under George W. Bush (Jacobson 2007). Until recently, the partisan 
difference in approval ratings had never exceeded 70 percent; since 2004, such large gaps between perceptions of opposing partisans have become commonplace. Feeling thermometer ratings also show a pattern of increased differences between individuals' feelings toward conservatives and liberals (Fiorina 1999, Jacobson 2000). Based on openended questions, Hetherington (2001) likewise reports that more Americans now have positive things to say about one party and negative things to say about the other.

To many scholars, findings of this kind suggest an increasing lack of respect for oppositional political groups. Moreover, some have blamed mass media, and television in particular, for promulgating polarization (e.g., Wilson 2006; Prior 2006). A variety of different theories have been used to suggest that television either helps or hurts the cause of mutual respect among oppositional political forces. In this study I focus on the unique visual perspective television provides on politicians and political advocates, and how this exposure may serve to either increase or decrease the legitimacy that partisans grant to oppositional political views.

In short, extensive theoretical work and some empirical studies acknowledge that while conflicts can and should arise over candidates and matters of public policy, the political system also must incorporate a means by which partisans can develop some degree of respect for the other side. If citizens remain unaware of any legitimate opposition, then political conflict itself seems petty and unnecessary (see Hibbing and Theiss-Morse 2002). Moreover, if the losing side in any given controversy perceives no legitimate basis for the positions of the winning side, then the losers are unlikely to cooperate in maintaining and perpetuating the rules of the game (see Anderson et al. 2005).

\section{TELEVISION AS A MEDIUM FOR POLITICAL DISCOURSE}


Television has both advantages and disadvantages as a source of exposure to oppositional perspectives. On the one hand, television is less subject to the constraints of parochialism that plague face to face interactions. Broadcast media have always reached much larger and more heterogeneous audiences than newspapers (Meyrowitz 1986).

Because people tend to live among those like themselves, their interactions are often limited in their ability to expose people to oppositional perspectives. Television transcends time and space in a way that makes less insular perspectives more widely available (Meyrowitz 1986). Indeed, despite general agreement as to the value of exposure to oppositional views, the limited potential for accomplishing this end in the realm of face to face discourse has led many to suggest that for most people, most of the time, exposure to opposing political perspectives happens via mass media (Calhoun 1988; Page 1996; Mutz and Martin 2001). Television's propensity to present controversial material in a point-counterpoint fashion insures that at least some opposing perspectives are heard.

On the other hand, it is probably naïve to expect exposure to oppositional views through television to easily convince partisans that their opposition is worthy. Watching others discuss opposing perspectives on television is qualitatively different from participation in face-to-face discussion, and the evidence on face-to-face deliberation is mixed in what it suggests about its outcomes (see Mendelberg 2002). Moreover, many such presentations on television are not discussions at all, but rather successive airings of opposing positions, often from people in different physical locations.

Some go so far as to suggest that in a country as large as the U.S., "We must accept a division of labor: that is, delegate the jobs of studying policy and addressing the public to a small set of representative or surrogate deliberators, perhaps to professional policy experts and communicators" (Page 1996: 4). Page suggests that the only practical solution is for professional communicators such as politicians, policy advocates or journalists to act for and 
represent the deliberation of ordinary citizens. In this fashion, oppositional views can reach citizens even when citizens are simply third party observers of others' conflicting views.

Mere exposure to alternative perspectives is only a first step along the road to attributing legitimacy to opposing views. After viewing the typical point-counterpoint format of so much televised political discourse, do citizens come away with a sense that the opposition has a legitimate basis for its views, or do viewers become still more convinced that the opposition is ill-motivated and/or unjustifiable? To be sure, not all televised political conflict is cut of the same cloth. For this reason I turn next to variations in televised political discourse and the differences these variations may make to the effectiveness of televised political discourse in legitimizing oppositional views.

\section{EFFECTS OF "IN YOUR FACE" DISAGREEMENT}

Can mass media make up for what Americans lack in face-to-face exposure to political discourse and thereby enhance the perceived legitimacy of the political opposition? There is ample room for skepticism on this point given the current nature of televised political discourse. Even in widely idealized face-to-face contexts, disagreements tend to be tense situations that do not always result in acknowledgement of the legitimacy of others'

positions. Granting legitimacy to those with whom one has significant differences of opinion is a complex and cognitively difficult task. To comprehend the logic and motivation behind views that are not one's own is an effortful, multi-step process (see Gilbert 1991). Two relatively common characteristics of televised political discourse may make this potential benefit less likely.

First, much of the political discourse that transpires on television is highly uncivil in tone. As Wilson (2006: 18) notes, "Once the media talked to us; now they shout at us." The usual social norms for politeness among those expressing differences of political opinion are 
routinely ignored on television (Mutz and Reeves 2005). Production values and intense market competition put a premium on conflict and drama. As a result, political advocates may come across as nasty, boorish sorts, particularly to those who do not find their views persuasive. Mutz and Reeves (2005) find that incivility in televised political disagreements produces systematically less trust in government and politicians than equivalent disagreements that transpire more politely. Clearly, there is something about incivility that rubs Americans the wrong way. But this study did not speak to the issue of whether viewers learn anything from listening to the opposition, or whether they come away with an enhanced appreciation for the merits of the other side as a result of their viewing.

What is known about incivility -whether in political discourse or some other contextis that it heightens levels of arousal (see Geen 1975; Mutz \& Reeves 2005). Arousal is closely tied to levels of attention, so one might expect uncivil political discourse to be especially well remembered. Indeed, those involved in the production of political television routinely argue that lively and passionate debate is a necessary ingredient for a successful television program involving political topics. Anything less is probably too boring to attract the attention of television audiences (see, e.g., Christianson 1986, Bradley et al. 1992, Christianson et al. 1986).

Beyond incivility, televised political discourse is also unique in the impression of greater intimacy that it creates. Few people will ever be physically as close to the public figures shown on televised political discourse as viewers feel themselves to be when watching television. As television cameras have become smaller and less obtrusive, and increasingly powerful due to technological advances, it has become common to show talking heads engaged in political repartee from an extremely close perspective. ${ }^{1}$ In the head shots that characterize much of televised political discourse, the cameras are zoomed in so close that even portions of the speaker's head are routinely cut off and out of frame. To obtain the 
same perspective on another person in real life, one would need to be virtually kissing him or her. In this sense televised political discourse can be described as doubly "in your face;" it is both unusually uncivil relative to everyday conversations, and it also creates the impression that, quite literally, the political speakers are "in your face," that is, unnaturally and uncomfortably close for a non-intimate acquaintance and public figure.

Research on face-to-face interaction suggests that the distance between people has important consequences for how people react, and this is particularly true with respect to the physical distance between two people who do not agree. In one study, Storms and Thomas (1977) showed subjects a mock survey supposedly filled out by a person the subject was about to meet. The surveys were rigged to convince each subject that the confederate's attitudes were either very similar to or highly dissimilar from his or her own, based on random assignment. Not surprisingly, a person assumed to be dissimilar in opinions was systematically less liked than one assumed to be similar. More interestingly, a second manipulation randomly assigned subjects to conditions in which the confederate sat unusually close to the subject, or across the table from him. When the confederate sat abnormally close to the subject, violating the norms for personal space, close physical distance interacted with attitude similarity to intensify attitudes toward the confederate (see also Schiffenbauer \& Schiavo 1976; Middlemist, Knowles \& Matter 1976).

This pattern of reactions to interpersonal distance has been well documented in the realm of face-to-face interaction. Dissimilarity breeds dislike, and closeness generally intensifies whatever kind of reaction - positive or negative - a person has to another person or object. This intensification of affect appears to be produced by the greater arousal that physical closeness produces (e.g., Smith and Knowles 1979, Middlemist, Knowles and Matter 1976). Higher arousal levels signal a greater intensity of emotional reaction, and the 
valence of the person or object - whether they are liked or disliked - produces the label that is assigned to that intensification.

If one extends this same logic to television, it suggests that perhaps one important thing television has changed about the way citizens experience political discourse is the proximity of their perspective on political advocates. Perhaps less physical distance--even when manifested through television cameras as the mere appearance of greater physical closeness between viewer and political advocate--has important consequences for how people react to the political discourse they see on television. Filmmakers have long recognized the potential for facial close-ups to intensify emotional reactions in the audience. As Russian film director Sergei Eisenstein (1940/1974) described it, "A cockroach filmed in close-up seems on the screen a hundred times more terrible than a hundred elephants captured in long shot." The close-up creates a sense of spatial intimacy that may violate individuals' boundaries for personal space, particularly when close contact with the person on the screen is undesirable.

Some empirical evidence corroborates Eisenstein's observation. For example, a person appearing on a large-screen television (and thus having the appearance of being larger and closer to the viewer) is more likely to invoke a violation of the viewer's sense of personal space than one on a smaller screen (Lombard 1995). Likewise, Reeves and Nass (1996) find that viewers' levels of attention and recall respond to mediated simulations of interpersonal distance (manipulated through the use of close-ups versus long shots, and through the size and distance of the image from the viewer) in much the same way that they do to interpersonal distance in face-to-face contexts. The conventions of television and film editing purposely seek to recreate familiar perceptual phenomena. Moreover, many editing devices "acquire ... meaning by approximating some feature of real world experience. In the case of shot tightness being used as an intensifier, the aspect of experience being 
replicated is surely the greater involvement that comes with increased proximity to people and objects ..." (Messaris 1994). Many of the conventions used in televised portrayals are based on analogies to real world experiences, so it should not be surprising that people react similarly to them.

The sense of threat experienced by television viewers is not likely to be a cognitive acknowledgment of some real threat; after all, few people would claim they feel imminent danger from a politician on a television screen. Instead, it is a subconscious feeling of threat based on the perception of being physically very close to someone who is disagreeable, and who thus presents an unwelcome invasion of personal space (Persson 1998). Sullivan and Masters (1987) have similarly argued that by creating a facsimile of real world visual experience, the visual element of television encourages "gut reactions" on the part of viewers, emotional reactions that are not mediated by cognitive assessments. ${ }^{2}$

\section{IN-YOUR-FACE POLITICS: A THEORETICAL FRAMEWORK}

What does political television's tendency to violate everyday norms of civility and personal space imply about its ability to serve as a source of information about a legitimate opposition? To the extent that political advocates of the opposing side create the impression of being uncomfortably close when featured in televised discourse, and/or unusually impolite, viewers should experience higher levels of emotional arousal. Arousal is, however, a double-edged sword. On one hand, some level of arousal is absolutely necessary in order to produce attention to the content of political discourse. ${ }^{3}$ The arousal produced by "in your face" political discourse should heighten levels of physiological arousal, and thus enhance attention to content and promote greater awareness of oppositional perspectives. Viewers cannot be expected to learn anything about oppositional perspectives unless they are paying attention. On the other hand, this same heightened level of arousal should intensify whatever 
affect a viewer already holds, thus producing greater dislike for an already disliked political advocate. The "in your face" perspective on political discourse that television often provides may increase viewers' awareness of oppositional perspectives and candidates, but simultaneously polarize attitudes toward opposing positions.

From a more positive, constructive angle, this theoretical framework suggests the conditions under which televised discourse might improve perceptions of the perceived legitimacy of the opposition. To the extent that televised political discourse is able to draw viewer attention, without intensifying opponents' already negative views toward one another, greater oppositional legitimacy should result. So under what conditions should exposure to televised political discourse have positive versus negative or neutral consequences for perceptions of the legitimacy of the opposition?

Relative to not watching at all, I expect televised exposure to oppositional perspectives to enhance the extent to which viewers are aware of oppositional arguments, regardless of the way in which these views are presented. The logic of this expectation is straightforward: no matter how arguments are presented, exposure to political discourse cannot reduce the level of awareness people have about arguments promoted by disliked candidates or about the rationales for what seem to them disagreeable policy positions. Viewers are likely to become more aware of oppositional perspectives from viewing.

But based on related psychological research, the increased arousal from "in your face" discourse also should intensify the negative affect viewers have for disliked people and political positions. When political advocates promote viewpoints with which a viewer disagrees, and do so in an "in your face" manner (i.e., uncivil discourse viewed from an intimate camera perspective), such presentations should detract from the legitimacy that citizen-viewers accord those oppositional perspectives. Just as in the face-to-face psychology experiment described above, non-like-minded people and policies should be 
even less well-liked when viewers are forced to experience disagreeable views from a highly intimate, "in your face" perspective. Likewise, well-liked people and their perspectives may be even more positively regarded as a result of the up-close and personal perspective.

Because this theoretical framework involves a complex, multi-step process, it is most easily evaluated by breaking it down into a series of specific hypotheses that build on one another. The first hypothesis is that close-up camera perspectives and incivility will both increase levels of emotional arousal. Mutz and Reeves (2005) found evidence supportive of this impact from incivility, but evidence to date on the effects of camera perspective is limited. Because the two additional hypotheses rest on this first hypothesis, it is crucial to validate it before examining the anticipated effects that arousal may have on awareness of oppositional rationales and their perceived legitimacy.

A second hypothesis following from the first is that heightened arousal will increase levels of recall. Thus the same independent variables that increase arousal-incivility and close-up camera perspectives-- also should enhance awareness of oppositional views that are heard via television. A third and final hypothesis is that close-up camera perspectives will interact with levels of civility in the same fashion as in the face-to-face experiment conducted by social psychologists. Relative to not watching at all, or to a medium camera perspective, close-up camera perspectives will intensify viewers' reactions to opposing political arguments and candidates. When they are presented in a likeable, civil fashion, viewers will see those arguments in favor of the opposition as even more legitimate, whereas viewers who witness an uncivil exchange will perceive the opposition as having even less legitimate rationales for their views than they would have otherwise. 


\section{RESEARCH DESIGN}

For purposes of examining these hypotheses, it was necessary to manipulate the camera perspective on the exact same political discourse, as well as to vary the level of civility expressed while holding all else constant. Toward that end, televised political discourse was presented to subjects in a laboratory setting using three experiments with adult subjects. In order to gain greater control over rival hypotheses and disentangle the effects of political substance versus presentation, the two independent variables were manipulated independently so that there were four versions of televised political discourse that differed in (1) whether the camera perspective suggests greater or lesser personal space between the viewer and the political advocates, and 2) the extent of civility/politeness in expressions of political differences.

In order to create political discourse suitable for these purposes, professional actors were hired, and a professional studio talk show set was used to tape an informal political discussion between what were said to be two congressional candidates. Subjects were told the candidates were running for an open congressional seat in a faraway state. A moderator intervened at times predetermined by a script, and addressed questions to the two candidates. Participants were simply asked to watch the program for 20 minutes and were told that they would be asked some questions about it after it was over.

The candidates held opposing views on each issue. In order to present literally the same political content in the civil and uncivil versions of the debate, the actors stuck closely to a script. ${ }^{4}$ In the complete forty minute exchange, a total of eight issues were discussed and debated, but participants were exposed to the discussion of a subset of four of these eight issues in each experimental study. To ensure that results did not hinge on any one particular segment of the program, a different subset of the eight discussions was used in each experiment. ${ }^{5}$ 
The candidates expressed exactly the same issue positions in the same words in both the civil and uncivil versions of this program, and they offered exactly the same arguments in support of their positions. The only departures from the script that were allowed for purposes of creating the variance in civility were nonverbal cues (such as rolling of the eyes), and phrases devoid of explicit political content (such as "You have completely missed the point here!"). The candidates in the uncivil condition also raised their voices and interrupted one another. In the civil version, the politicians spoke calmly throughout, and were patient and respectful while the other person spoke.

To insure that these relatively subtle differences adequately manipulated civility, pretest subjects were asked to rate the candidates on scales ranging from quarrelsome to cooperative, friendly to hostile, and rude to polite. The uncivil versions of the issue exchanges were consistently perceived as significantly less polite, more quarrelsome, and less friendly. As a manipulation check, respondents in each of the actual experiments also were asked to rate the candidates on these same scales. As in the pretest, these items confirmed that both candidates were seen as significantly more hostile and rude in the uncivil conditions than in the civil ones. The camera perspective manipulation was made possible by shooting both the civil and uncivil tapings using four simultaneous cameras. For each exchange of opinions, one camera maintained a medium range shot of the speaker's upper body, while another camera maintained a tight facial close-up of the same person. Two additional cameras did the same for the other candidate. The tapes were later edited using the same conventions as for a typical talk show. After an initial long shot established the set and the location of the candidates and moderator, the subsequent shots were almost exclusively tight close-ups in close-up version. In the medium version, the same event was simply shown from the perspective of cameras that had backed in their framing of the participants, and no tight close-ups of the candidates were included in the medium camera 
version. This process produced four different versions of the same political discourse that were either civil or uncivil in tone, and that either created the impression of moderate physical distance between the viewer and candidates or a close-up "in-your-face" experience of the same conflict.

Procedures. Procedures were roughly the same in all experiments. Participants were recruited through temporary employment agencies and community groups and either the group treasury or the participants were compensated for their time. ${ }^{6}$ After consent was obtained, subjects sat on a couch in front of a television screen and filled out a pretest questionnaire. They then viewed a segment of the program involving four of the eight issue exchanges. A paper and pencil questionnaire was administered after viewing.

The first experiment was designed to determine whether camera perspective and televised incivility produce the same reactions that physical distance and disagreement do when experienced in person. Toward that end, Experiment 1 utilized a powerful Latinsquare design and a small sample of 16 subjects, each of whom experienced all four possible conditions formed by crossing incivility/civility and close/medium camera distance. By rotating subjects through all possible issue by condition combinations, it was possible to compare each individual's reactions across the four conditions. The Latin square design is particularly advantageous in studying arousal because individual differences in arousability tend to be quite large, thus making the within group variance extremely large. The Latin square design allows comparisons of each subject to their own mean level of arousal across the four conditions and enabled us to determine whether viewers' levels of arousal varied systematically due to close-ups and incivility.

Arousal was measured using skin conductance levels (SCL) assessed by attaching two electrodes to the palm of each subject's non-dominant hand while he or she watched the videotapes. Skin conductance is one indicator of sympathetic activation (Hopkins \& Fletcher 
1994), and has been widely used in studies investigating emotional responses to media (see Reeves \& Nass1996, or Lang 2000 for examples). Data collection began at the start of each tape, with a 10-second period of baseline data recorded while the screen was blank prior to the start of each debate segment. The intensity of emotional reactions to these stimuli forms the theoretical basis for the subsequent effects. However, given that all subjects were in all of the four conditions, the within-subject design of Experiment 1 did not allow us to assess the effects of these manipulations on the perceived legitimacy of oppositional views.

To address that question, Experiment 2 utilized a large sample of 155 participants who each were exposed to only one of the four possible experimental conditions formed by crossing civility/incivility with close-up versus medium camera perspective. Participants were randomly assigned to watch twenty minutes of televised political discourse that covered four issue disagreements. This between-subject design facilitated use of recall and post-test measures of the legitimacy accorded to the other side. In addition, Experiment 2 included a control group in order to determine whether citizens' perceptions of the legitimacy of the opposition benefit from or are harmed by televised political discourse relative to not watching at all. The participants randomly assigned to the control group watched a non-political program for the same amount of time that the treatment groups watched the issue debates.

Dependent variables. Three main concepts were measured and analyzed in this study. Arousal was tapped using the SCL data described above, which was sampled from subjects every 10 milliseconds, and then averaged for each subject within each experimental condition. ${ }^{7}$ Awareness of rationales for oppositional positions was measured using openended recall measures in the post-tests, which asked respondents to write down all arguments they could remember the candidates having made in support of or in opposition to a given issue position. Respondents were asked, "What are some of the reasons people 
are in support of [stated position]? Please write as many reasons as you can think of in the box below." The goal was to assess the extent to which respondents' recall of rationales for their own and the opposing viewpoint were affected by the experimental manipulations. For each respondent, separate measures were created corresponding to recall of arguments on the side he or she opposed or favored; in other words, the number of legitimate arguments respondents could generate for the "other" side, as well as their own. ${ }^{8}$ Although simple recall of oppositional arguments is not the same thing as granting legitimacy to oppositional views, having some awareness of arguments on the other side is an important prerequisite to granting them legitimacy.

A third concept, Perceptions of the legitimacy of the opposition, was operationalized in two ways. First, I assessed people's feelings toward the politician they least favored in order to get a sense of how the size of the gap between the preferred and non-preferred candidate was affected by the experimental manipulations. When people retain a degree of respect for the opposing candidate, they support the notion of a legitimate opposition, and work against the forces of polarization. This measure was based on subjects' feeling thermometer ratings of the candidate for whom they said they would be least likely to vote. For a political process to create legitimacy, it must foster preferences for one candidate without demonizing the opposition. Thus the attitudes people hold toward their non-optimal candidates also matter because some portion of the time they can expect their government leaders to be other than their preferred candidates (see Bowler and Donovan 2003). Given that people react negatively to those with whom they disagree, this theory predicts that they should react particularly negatively toward candidates they do not like when those people violate norms for civility and distance.

A second measure of the perceived legitimacy of the opposition involved a series of closed-ended questions assessing respondents' perceptions of the legitimacy of the two 
candidates' arguments. After completing the open-ended portion of the questionnaire, participants were asked to judge the general strengths and weaknesses of a list of arguments, regardless of the respondents' own personal views on the issue. For each of the four issue segments they viewed, the closed-ended items listed six of the arguments that were featured in the program (three made by each candidate). Subjects were then asked to label each argument as a "Very strong argument, somewhat strong argument, a somewhat weak argument, or a very weak argument." Although people naturally rate the arguments in support of their own side of an issue as stronger than those on the other side; the interest for purposes of this study is in whether in your face politics alters the level of legitimacy accorded to the opposition. These items were used to create scales indicating respondents' assessments of the legitimacy of arguments made on behalf of the issue positions they themselves favor, as well as the legitimacy of arguments on the opposing side. The scales used to tap these dependent variables all achieved respectable levels of reliability (see Appendix A).

\section{RESULTS}

Experiment 1. To what extent does "in your face" political discourse increase viewers' levels of emotional arousal? Figure 1 shows the average skin conductance level for each of the four experimental conditions in the Latin square design. Consistent with expectations, there were clear differences between conditions for both experimental factors. Uncivil public discourse was significantly more arousing than civil versions of the same discussions $(\mathrm{t}=14.38 ; \mathrm{df}=1,299 ; \mathrm{p}<.001)$. The analysis of different camera perspectives likewise confirmed that close-ups of the exact same events were significantly more arousing to viewers than the same event shown using medium shots $(t=28.90 ; d f=1,299 ; p<.001)$.

[Figure 1 here] 
As anticipated, uncivil exchanges of political views featuring tight close-ups were most arousing of all, and highly civil exchanges shown through medium shots were least arousing. Given that politics is not a highly arousing topic for most people, these differences may well explain why audiences are willing to watch so-called "shout shows" on television. Mutz and Reeves (2005) reported a puzzling finding suggesting that people reported a greater intent to watch uncivil programs than civil ones, yet the same people appeared to judge the uncivil politicians quite negatively after viewing. People may genuinely dislike the behavior they observe, and judge the participants negatively as a result, but they are clearly very arousing to watch, and all the more so when disagreement is of the "in your face" variety. Given their highly arousing content, attention levels to such programs are naturally quite high, whether they like them or not. But it remains to be seen whether these differential levels of arousal have implications for the processing of televised political discourse. Arousal is widely accepted as an indicator of attention, but it reveals nothing about what people learn from the content, nor the valence of people's reactions to what they learn. For these purposes, a second experiment was required.

Experiment 2. For the second study, a much larger number of participants was recruited in order to facilitate a five condition between-subjects design. With each subject in only one condition, it was possible to assess the effects of the independent variables on recall of issue arguments for own and opposing issue perspectives, as well as for effects on the legitimacy of those same arguments. Results were examined using an analysis of variance with planned contrasts between the experimental conditions and the control group, and a two by two full factorial analysis of variance.

Awareness of Rationales for Own and Opposing Issue Positions. Figure 2 shows the extent of awareness of arguments supporting one's own issue positions on the right, and of 
others' issue positions on the left. A full-factorial analysis of variance of the experimental conditions revealed a significant interaction between the civility/incivility and camera perspective. As shown in Figure 2, regardless of whether one considers recall of arguments supporting own or others' issue positions, the patterns are virtually identical. Recall of arguments was enhanced by the same factors that enhance arousal: incivility and a close-up camera perspective. For awareness of oppositional issue arguments, the interaction of incivility and close-up camera perspective was significant $(F=4.36, p<.05)$. For awareness of arguments on one's own side, only incivility significantly enhanced recall $(F=5.13, p<.05)$, though the pattern is very similar to the left-hand side of Figure 2. The uncivil, close-up conditions consistently stand out in producing higher levels of recall.

Focusing next on comparisons with the striped, control conditions in the center of the left and right panels, there is clear evidence that viewers learned something about the issue controversies from watching the program. Analysis of variance results suggest that awareness of issue arguments on one's own side is improved by the experimental versions of the program, regardless of whether viewers watched civil or uncivil, close-up or medium versions. Those who watched consistently knew more than those who did not. All planned contrasts between each of these groups relative to the control condition were significant $(p<.05)$

On one hand, this finding is simply consistent with previous evidence of television's capacity to inform the electorate; people learned something from watching (e.g. Baum 2003). But it supports the notion that television may play an important role in educating the public on the views of people outside their immediate environments, and on the arguments these others use to support those oppositional positions.

[Figure 2 here] 
Attitudes Toward the Opposition. The findings thus far on arousal, and on recall/awareness of oppositional views are basically supportive of the idea that televised public discourse may play an important role in making people aware of oppositional issue perspectives, and possibly in legitimizing oppositional political perspectives as well. How might one know that the opposition was seen as more legitimate as a result of viewing political discourse? Although political preferences themselves would not change, one can imagine that effective exposure to oppositional views should produce less villainization of the opposing side. Thus as a first test of this hypothesis, I examined the gap between viewer attitudes toward their preferred candidate and the alternative candidate. There is no significant pattern of attitudes toward the two individual politicians based on whether subjects viewed civil or uncivil, close-up or medium versions of the stimuli. However, as shown in Figure 3, differences in the thermometer ratings between the preferred and non-preferred candidate confirmed the hypothesized pattern specifically when subjects were shown the close-up version of political discourse. When the uncivil candidates were shown in closeups, the gap between evaluations of the two candidates was exacerbated, just as close-up disagreement from another live human being intensified attitudes in the laboratory. However, the very same means for subjects watching the exact same event from a medium camera perspective did not differ. Consistent with appearances, these findings produced an interaction between civility and camera distance $(F=4.84, p<.05)$.

In short, levels of candidate civility made a big difference when shown to viewers in an up-close and personal manner, but no difference at all from a more distant perspective. Interestingly, the findings in Figure 3 are driven primarily by differences in the evaluations of the least-liked candidates. Attitudes toward the preferred candidate did not vary significantly by condition. The greater gap between evaluations of the preferred candidate and his opposition is driven by attitudes toward the opposition. Regardless, this pattern is indicative 
of the same kind of polarization that concerns many observers of American politics (see, e.g., Jacobson 2007). It is troubling when the opposition is so much less liked than the preferred candidate, but as often as not, citizens will need to live under the government of someone who was not their choice.

[Figure 3 here]

The Perceived Legitimacy of Opposing Arguments. Relative to the control group, the people who watched televised political discourse came away from the experience better able to recount the other side's arguments as well as their own. One would hope that this result translates into a sense that theirs is not the only legitimate way to think about the political world. But open-ended recall is clearly not the same as perceiving those oppositional arguments to be legitimate ones. For this purpose, I compared means for the direct assessments of the perceived legitimacy of arguments made on both sides.

There were no significant differences by experimental condition in analyses examining the perceived legitimacy of arguments supporting one's own views. Regardless of whether political discourse was viewed from a close or medium perspective, and regardless of whether the political advocates were civil or uncivil, respondents viewed the arguments on their own side of these issues as just as legitimate. This result parallels the finding for attitudes toward most and least-liked candidates. The manipulations had no discernible effect on what respondents knew they liked.

However, as with the findings on liking for candidates, the manipulations had a significant impact on perceptions of the value of the "other side." As shown in Figure 4, the four conditions within the two by two factorial design produced a significant interaction between civility and camera distance $(F=6.41, p<.05)$. Levels of civility mattered a great deal to perceptions of the legitimacy of opposition views when subjects viewed the uncivil 
exchange in one of the close-up conditions. This interaction demonstrates that when viewed up close and personal, people found the very same arguments espoused in the civil version of the debate more legitimate than those in the uncivil one. If viewed from a medium camera perspective, civility made no difference.

[Figure 4 here]

The presence of the control condition shown in the center of Figure 4 also makes it possible to assess whether watching this program helped or hurt the perceived legitimacy of arguments on the other side relative to not watching at all. Planned comparisons suggest that the mean in the control condition is statistically indistinguishable from the means for both of the medium conditions on the right hand side of Figure 4. But on the left-hand side of Figure 4, the mean of the close-up, uncivil condition shows significantly less perceived legitimacy than the control condition, and the mean for the close-up, civil condition indicates significantly greater perceived legitimacy relative to the control condition (omnibus $F=7.10$, $\mathrm{p}<.01$; contrast between civil and control, $\mathrm{p}<.01$, contrast between uncivil and control, $\mathrm{p}<.001)$.

These contrasts make it possible to draw conclusions about the effects of viewing different styles of televised political discourse relative to not watching at all. Even though subjects in the close-up and medium conditions were viewing precisely the same exchange, the perceived proximity of the politicians led to less favorable evaluations of the disagreeable issue arguments in the uncivil exchange, and more favorable evaluations in the civil one. These results nicely mirror previous findings on the intensifying effect of physical proximity in face-to-face situations. When disagreeable issue positions are espoused by a civil person in close-up, they are viewed as more legitimate than they otherwise would be. When disagreeable positions are espoused by an uncivil person, they are viewed as less legitimate than they otherwise would be. 
To summarize the results of Experiment 2, these findings suggest that television political discourse does have the capacity to improve citizens' awareness of oppositional views, and the extent to which opposition is perceived as having a legitimate basis for their views. But "in your face" politics is, indeed, a double-edged sword. The intimacy of the television camera can enhance the perceived legitimacy of oppositional views when they are presented in a civil manner. When they are presented in an uncivil manner, that same intimacy convinces people that the opposition is even less legitimate than they would have thought without any viewing.

Thus far these findings are limited to results from one small and one large experiment. To assess the generalizability of these findings to other populations and issue conflicts, a third experiment was conducted with a completely different set of stimuli. Experiment 3 was designed to replicate the important findings in Experiment 2. To reduce the number of subjects required, participants were randomly exposed to one of only two conditions this time, either close-up versions of civil discourse or close-up versions of uncivil discourse. Given that these were the two conditions that produced significant differences from the control condition in Experiment 2, a similar pattern of results in Experiment 3 would lend greater confidence in these findings.

Figure 5 analyzes the results of Experiment 3 to see whether subjects in the uncivil/close-up condition systematically evaluated their least-favored candidate more poorly than subjects in the civil/close-up condition, as was the case in Experiment 2. As illustrated, there was no difference in feelings toward the candidate each subject liked the most as a result of viewing them behaving in an uncivil manner. However, the opposition is systematically judged more negatively in the uncivil condition relative to the civil one. As a result, just as in Experiment 2, the gap between the favored and the non-favored candidate is far larger after viewing uncivil political discourse. Uncivil behavior on the part of one's own 
side is dismissed as mere righteous indignation in the face of an uncivil opponent; when the other side engages in similar behavior, it is a sign of their depravity. Interestingly, precisely this same kind of data on gaps between evaluations of one's own side and the opposition is cited in historical context to argue that polarization has increased in the United States (see Jacobson 2007).

In Table 1, I use data from the legitimacy items in Experiment 3 to examine the closely-related hypothesis for issues, rather than for candidates. Does exposure to close-up, uncivil discourse reduce the legitimacy attributed to oppositional arguments? The results in Table 1 illustrate basically the same pattern of results as in Figure 2. Using a regression equation that controls for a variety of demographic characteristics as well as for general awareness of the rationales for these issue positions, Table 1 suggests that incivility has no effects on the number of rationales people recall for their own side of these controversies. However, as shown in the right column, incivility has a significant negative impact on awareness of rationales for oppositional views. As in Figure 5, this pattern of results means that the balance of arguments and justifications that a person takes away from viewing televised political discourse are even more imbalanced as a result of "in your face" exposure to political discourse.

\section{DISCUSSION: REMEMBERING MORE AND LIKING IT LESS}

Based on these studies, people do appear to learn from political television, and this includes learning about why others hold the opinions that they do. Subjects recalled significantly more rationales for oppositional views as a result of viewing even highly uncivil political discourse. For those citizens who find it difficult to fathom how others might reasonably hold views other than their own - an increasingly sizable group according to many sources, televised political discourse is undoubtedly serving an important purpose. 
These effects are encouraged by the kind of lively repartee that often characterizes today's political programs. Close-up perspectives on uncivil exchanges of political views are arousing for viewers to watch, and thus help to draw audiences to these programs, as well as to encourage attention and retention while viewing. To be sure, levels of attention are likely to be abnormally high in a laboratory setting, so the levels of recall reported here would probably be somewhat less impressive in real world viewing settings. On the other hand, civil and uncivil political programs would probably not draw equally-sized audiences in the real world either; uncivil programs would draw larger audiences and thus have the potential to educate more viewers about oppositional views. Generalizability issues could thus cut both ways when projecting these findings to real world contexts.

When seen exclusively from this perspective, televised political discourse would seem to be in the service of a deliberative body politic. People may not be conversing with friends or neighbors who hold opposing views, but at least they hear about them on television. As the control group comparisons suggest, any exposure is better than nothing when it comes to what people know about why the political opposition feels the way they do.

But the most important and noteworthy findings become apparent when the analysis turns to people's evaluations of those same candidates and their issue arguments. Incivility alone does not dampen enthusiasm for political advocates nor the arguments they make. However, when incivility and close-up camera perspectives combine to produce the unique "in your face" perspective, then the high levels of arousal and attention come at the cost of lowering regard for the other side. The intimacy of uncivil political discourse on television discourages the kind of mutual respect that might sustain perceptions of a legitimate opposition. Here the pattern of findings is quite consistent; close-up perspectives on uncivil discourse routinely damage perceptions of the candidates and issue arguments that subjects are already prone to dislike; that is, attitudes toward the least-liked candidate, and the 
perceived legitimacy of rationales for opposing issue positions. The same pattern of effects did not occur for attitudes toward the preferred candidate, nor for perceptions of the legitimacy of arguments for the preferred issue position. The overall effect of these two patterns is to increase the magnitude of the difference that is perceived between one's own side and the opposition.

From one perspective, this pattern might call for downplaying the real world significance of these effects; after all, what difference does it make if people have even greater dislike for candidates or ideas that they are already inclined to oppose? But the implications are important because of the need for people to be aware of, and hold some degree of respect for, people and views other than their most preferred choices. In short, these differences matter for the legitimacy of any multi-party, pluralist system. A willingness to acknowledge that there is something to be said for the other side, even when one's own views do not prevail, is essential to the kind of legitimacy that allows a democratic political system to remain stable. ${ }^{9}$

Do these findings suggest that characteristics of contemporary political television may encourage mass polarization? The answer to this question depends upon how one defines polarization. The evidence in this study does not speak to the notion of citizens endorsing increasingly extreme issue positions. But to many scholars, what these experiments demonstrate is precisely what political polarization is all about. As Wilson (2006: 15) defines it, "Such a condition is revealed when a candidate for public office is regarded by a competitor and his supporters not simply as wrong but as corrupt or wicked; when one way of thinking about the world is assumed to be morally superior to any other way; when one set of political beliefs is considered to be entirely correct, and a rival set wholly wrong." In this sense of the term, the intimacy and adversarialness of contemporary political television does, indeed, encourage mass polarization. Citizens may not have more 
extreme views about their own policy preferences, but they are convinced that the opposition is completely unworthy and illegitimate. To recall the question Dave Barry posed before the introduction of this article, one would have to answer with a resounding "Yes."

These results also hint at possible historical changes in the way citizens respond to candidates and political advocates in an age of televisual politics. Although there is widespread agreement among political pundits that television has changed American politics in some fundamental way, scholars have been hard-pressed to figure out and document exactly how television is different from other media in its political implications (see e.g., Schudson 1995). When early content analyses showed that television's political content was basically the same as that of newspapers, proponents of television's exceptionalism had to take note. Likewise, there was and is no compelling evidence that television is clearly more effective in persuading viewers than print media. But the content of television is more than merely the words spoken. When viewers develop a sense of intimacy with public figures whom they have never met, and with whom they may have emphatic disagreements, strong emotions are not surprising. Visual intimacy and the arousal it brings with it serve to intensify feelings. Thus one of the legacies of political television may be to virtually eliminate the quaint notion of a "worthy opposition." To the extent that televised political discourse intensifies feelings about political advocates, it does not serve the goals of consensus or compromise.

In the realm of politics, television may be the primary engine of what Sennett (1977) mor generally terms "the fall of public man." When private relationships become indistinguishable from public ones, and public figures are routinely talking to us in our living rooms as are politicians, then a boundary is crossed that makes our judgments of them far less impersonal. According to Sennett, the contemporary United States is overwhelmed by a "tyranny of intimacy," meaning that private individuals feel they know public figures in 
intimate terms. Although Sennett's argument is not about television per se, it seems very likely that we experience public figures very differently from how they were encountered in a pre-television era.

Seeing politicians argue about their disagreeable policies up-close and personal rather than from a distance intensifies citizens' negativity toward those people and ideas that they dislike. In the days when such intimate perspectives were not technologically possible, as when exposure to politicians was limited to newspapers, or when extreme close-ups of candidates were technologically difficult, the intensity of our disgust for those with whom we disagree might have remained more muted.

These findings validate the important role that emotion plays in understanding the processing of political television. The effects observed in these studies depend upon gutlevel affective reactions. As anyone who has been cornered by a disagreeable individual at a cocktail party knows, this experience tends to be unpleasant at best. The natural reaction for most people is to want such individuals out of their faces as soon as possible. It is one thing if the person is espousing his or her disagreeable views on the other side of the room, and quite another if they insist on doing so at close range. So although television can carry the same information as any other medium, the emotional impact of televised political discourse is quite different from what one would expect from a print source, and different as well from television that frames public figures from more of a distance. Television replicates the sound and sight of human experience so that today's political advocates can, for better or worse, truly be in our faces. 


\section{Appendix A: Construction and Reliability of Indices}

\section{Feeling Thermometers:}

"Using our "Feeling Thermometer", where 0 means you feel extremely cold toward the candidate and 100 means you feel extremely warm toward him, how do you feel about [Candidate Name] based on viewing the talk show?"

"Using the same feeling thermometer, how do you feel about [Candidate Name] based on viewing the talk show?"

\section{Perceived Legitimacy of Arguments}

"Regardless of your own view on this issue, we would like you to tell us how strong or weak an argument you think each of the following reasons is." All arguments listed were drawn directly from the statements made by the candidates. Three examples of the 24 items used for these purposes in each experiment include (for the issue of further regulating tobacco advertising): "The government has a legitimate interest in reducing smoking because it costs the healthcare system a huge amount of money every year." A four-point scale ranged from "very strong argument" (3) to "very weak argument" (0). "Cigarettes are legal, so the government should not regulate them more harshly than other products such as alcohol." (same scale as above). "Banning tobacco advertising violates the principle of free speech" (same scale).

Six separate reasons were listed for each issue, three in support of one side, and three in support of the other side. The average strength ratings for items on one's own side of the issue were combined across the four issues, and the same was done for arguments supporting the side opposite the respondent's own view. Thus perceived legitimacy was based on 12 items for own side and another 12 items for the other side. Pretest issue opinion questions were used as the basis for deciding what subjects' preferences were for 
each issue. If a subject had no view on any given issue, then Own and Other Side were randomly assigned.

\section{Awareness of Arguments}

"What are some of the reasons [Candidate Name] gave in support of his opinion on the talk show? Please write as many as you can think of in the box below." Coded for total number of arguments correctly recalled on own and other side of issue. 


\section{REFERENCES}

Anderson, Christopher J., Blais, Andre, Bowler, Shaun, Donovan, Todd and Ola Listhaug. 2005. Losers' Consent: Elections and Democratic Legitimacy. New York: Oxford University Press.

Arendt, Hannah. 1968. Between Past and Future: Eight Exercises in Political Thought. New York: Viking Press.

Baum, Matthew A. 2003. Soft News Goes to War: Public Opinion and American Foreign Policy in the New Media Age. Princeton, NJ: Princeton University Press.

Benhabib, Seyla 1992. Situating the Self. New York: Routledge.

Bowler, Shaun, and Todd Donovan. 2003. The Effects of Winning and Losing on Attitudes about Political Institutions and Democracy in the United States. Paper presented to the Midwest Political Science Association Meeting, Chicago, IL, April 3-6.

Bradley, M.M., Greenwald, M.K., Petry, M.C., and P.J. Lang. 1992. Remembering Pictures: Pleasure and Arousal in Memory. Journal of Experimental Psychology: Learning, Memory and Cognition 18(2): 379-90.

Brown, P. and S.C. Levinson. 1987. Politeness: Some Universals in Language Usage. Cambridge University Press.

Burgoon, J.K. and Stephen B. Jones. 1976. Toward a Theory of Personal Space Expectations and Their Violations. Human Communication Research 2: 131-46.

Calhoun, Craig. 1988. Populist Politics, Communications Media and Large Scale Societal Integration. Sociological Theory 6: 219-241.

Christianson, S.A. 1986. Effects of Positive Emotional Events on Memory. Scandinavian Journal of Psychology 27: 287-99.

Christianson, S.A., Nilsson, L.G., Mjorndal, T., Perris, C., and G. Tjellden.1986.

Psychological Versus Physiological Determinants of Emotional Arousal and Its Relationship to Laboratory-Induced Amnesia. Scandinavian Journal of Psychology 27: 300-10.

Eisenstein, S.M. (Edited and translated by Jacques Aumont)1940/1974. En Gros Plan. In Au-dela des etoiles. Paris: Union Generale d'Editions.

Fallows, J. 1996. Breaking the News: How the Media Undermine American Democracy. New York: Pantheon.

Fearon, James. 1998. "Deliberation as Discussion." In Deliberative Democracy, ed. Jon Elster. New York: Cambridge University Press, Pp. 44-68. 
Fiorina, Morris P., with Samuel J. Abrams and Jeremy C. Pope. 2004. Culture War? The Myth of a Polarized America. New York: Longman.

Fiorina, Morris P. 1999. Whatever Happened to the Media Voter? Paper presented to the MIT Conference on Parties and Congress, Cambridge, MA. October 2.

Fleisher, Richard and Jon R. Bond. 2004. The Shrinking Middle in the U.S. Congress. British Journal of Political Science 34: 429-51.

Geen, Russell G. 1975. The Meaning of Observed Violence: Real vs. Fictional Violence and Consequent Effects on Aggression and Emotional Arousal. Journal of Research in Personality 9 (4): 270-281.

Gilbert, Daniel T. 1991. How Mental Systems Believe. American Psychologist 46(2): 107119.

Gilligan, Stephen G., and Gordon H. Bower. 1984. Cognitive Consequences of Emotional Arousal, in Emotion, Cognition and Behavior, Carroll Izard et al. (eds.), New York: Cambridge.

Hetherington, Marc J. 2001. Resurgent Mass Partisanship: The Role of Elite Polarization. American Political Science Review 95:619-631.

Hibbing, John R. and Elizabeth Theiss-Morse. 2002. Stealth Democracy. New York: Cambridge University Press.

Hopkins, R., and Fletcher, J. E. 1994. Electrodermal measurement: Particularly effective for forecasting message influence on sales appeal. In A. Lang (Ed.), Measuring Psychological Responses to Media Messages (pp. 113-132). Hillsdale, NJ: Lawrence Erlbaum.

Jacobson, Gary. 2007. A Divider, Not a Uniter: George W. Bush and the American People. New York: Pearson Longman.

Jacobson, Gary. 2000. The Electoral Basis of Partisan Polarization in Congress. Paper presented at the Annual Meeting of the American Political Science Association, Washington, DC.

Lang, Annie. 2000. The Limited Capacity Model of Mediated Message Processing. Journal of Communication 50(1): 46-70.

Loftus, Elizabeth F., and Terrence E. Burns. 1982. Mental Shock Can Produce Retrograde Amnesia. Memory and Cognition 10(4): 318-23.

Lombard, Matthew. 1995. Direct Responses to People on the Screen: Television and Personal Space. Communication Research 22 (3), 288-324.

Lombard, Matthew, Reich, Robert D., Grabe, Mary E., Bracken, Cheryl C., and Theresa B. Ditton. 2000. Presence and Television: The Role of Screen Size. Human Communication Research 26 (1) 75-98. 
Manin, Bernard. 1987. "On Legitimacy and Political Deliberation", Political Theory 15 (3): 338-368.

Mendelberg, Tali. 2002. "The Deliberative Citizen: Theory and Evidence." In Michael X. Delli Carpini, Leonie Huddy, and Robert Y. Shapiro (Eds.), Political Decision Making, Deliberation and Participation: Research in Micropolitics, Volume 6. Greenwich, CT: JAI Press.

Messaris, P. 1994. Visual "Literacy:" Image, Mind and Reality. Boulder: Westview Press.

Meyrowitz, Joshua. 1986. No Sense of Place: The Impact of Electronic Media on Soical Behavior. New York: Oxford.

Middlemist, R.D., Knowles, E.S., and C.F. Matter. 1976. Personal Space Invasions in the Lavatory: Suggestive Evidence for Arousal. Journal of Personality and Social Psychology 33: 541-6

Mutz, Diana C. and Paul Martin. 2001. Facilitating Communication Across Lines of Political Difference: The Role of Mass Media. American Poitical Science Review, 95(March): 97-114.

Mutz, Diana C. and Byron Reeves. 2005. The New Videomalaise: Effects of Televised Incivility on Political Trust. American Political Scence Review 99(1): 1-15.

Page, Benjamin I. 1996. Who Deliberates?: Mass Media in Modern Democracy. Chicago: University of Chicago Press.

Persson, P. (1998). "Towards a Psychological Theory of Close-ups: Experiencing Intimacy and Threat." In KINEMA. A Journal for Film and Audiovisual Media (Spring 1998), University of Waterloo, Ontario, Canada, pp. 24-42.

Prior, Markus. 2006. Post-Broadcast Democracy. Book manuscript, forthcoming from Cambridge University Press.

Reeves, B. \& Nass, C. 1996. The Media Equation: How People Treat Computers, Television and New Media Like Real People and Places. New York: Cambridge.

Schiffenbauer, A., and R.S. Schiavo. 1976. Physical Distance and Attraction: An Intensification Effect. Journal of Experimental Social Psychology 12: 274-82.

Schudson, Michael. 1995. Trout or Hamburger: Politics and Telemythology. Chapter 5 in The Power of News. Cambridge: Harvard University Press.

Sennett, Richard. 1977. The Fall of Public Man. New York: Knopf.

Smith, Robert J., and Eric S. Knowles. 1979. Affective and Cognitive Mediators of Reactions to Spatial Invasions. Journal of Experimental Social Psychology 15: 437-52.

Storms, M.D., and G.C. Thomas. 1977. Reactions to Physical Closeness. Journal of Personality and Social Psychology 1977: 412-28. 
Sullivan, Denis G., and Roger D. Masters. 1987. Emotional and Cognitive Reactions to Watching Political Leaders: Experimental Evidence in France and the United States.

Presented to the $10^{\text {th }}$ Annual Meeting of the International Society of Political Psychology, San Francisco, CA.

Wilson, James Q. 2006. How Divided Are We? Commentary (February 2006): 15-21. 


\section{Table 1. Effects of Civility on the Perceived Legitimacy of Rationales}

Supporting Own and Opposing Issue Positions.

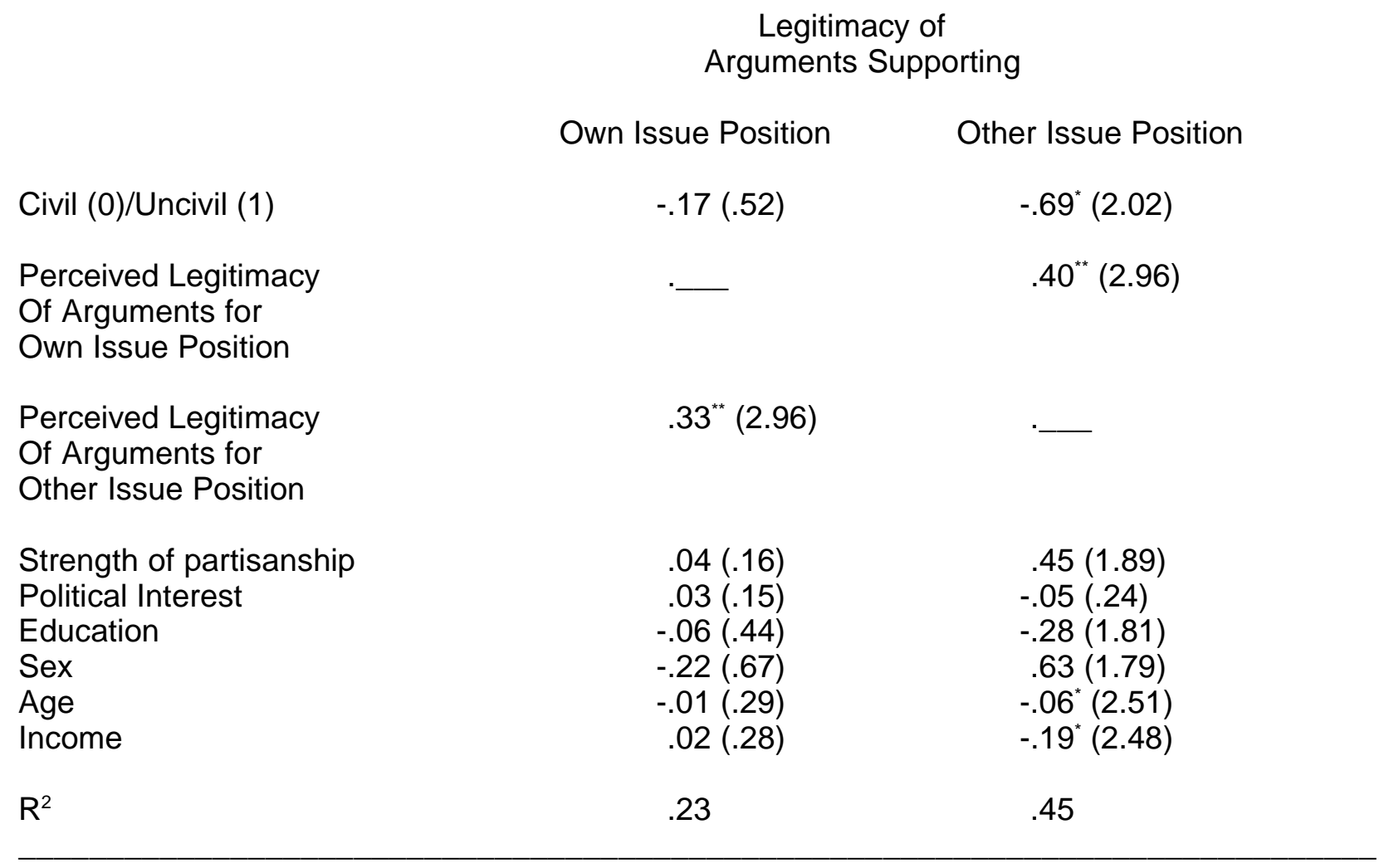

Note: Entries are OLS regression coefficients with t-values in parentheses. Dependent variables represent the sum of the mean strength of argument scores for each of the four issues discussed, broken down by arguments supporting the respondent's own issue positions, and those supporting the opposing position. 


\section{Figure 1. Emotional Arousal by Civility and Camera Perspective}

(Experiment 1).

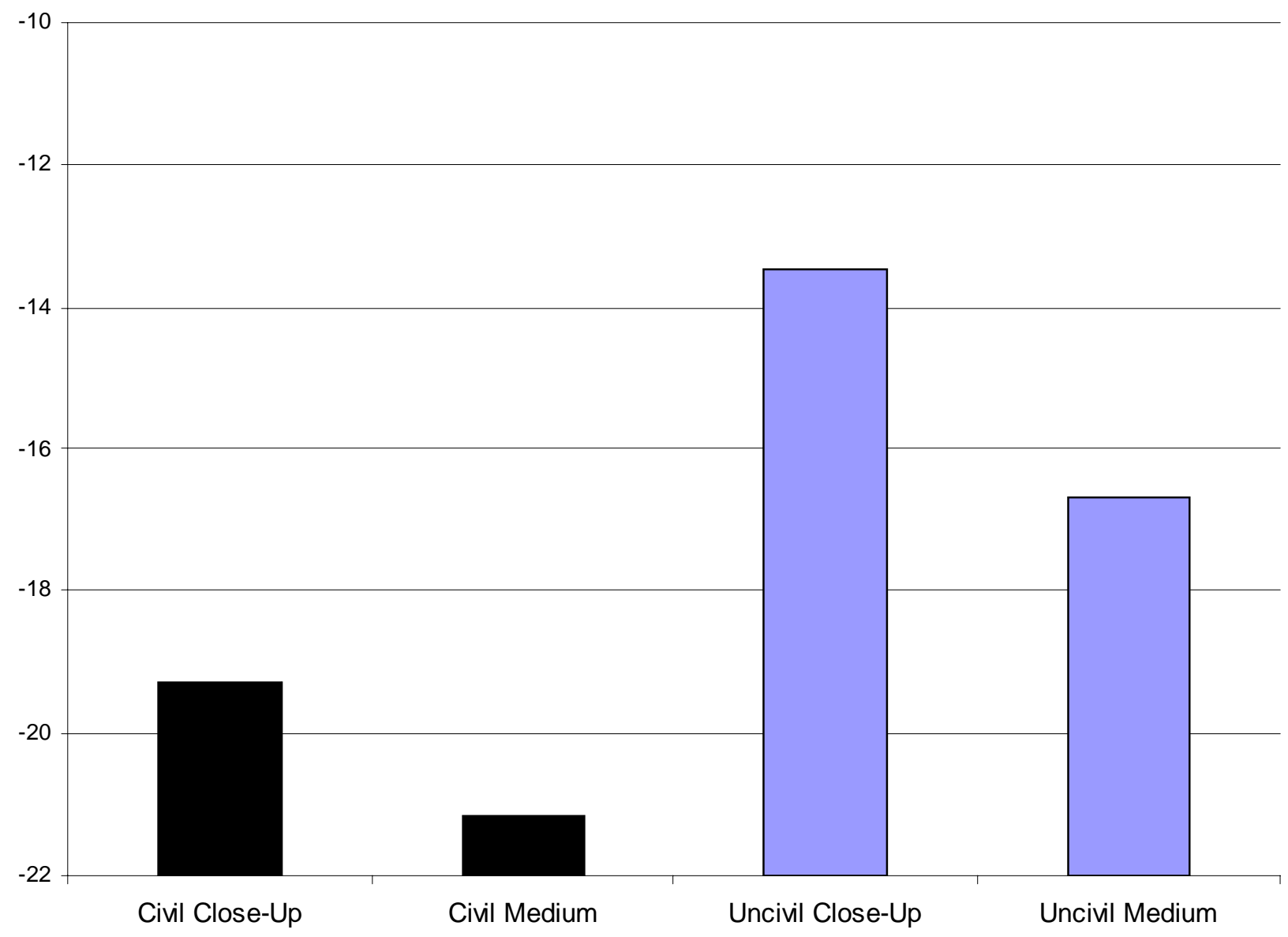

Note: Dependent variable was measured using skin conductance. A repeated measures analysis of variance indicated that uncivil discourse was significantly more arousing to viewers than a civil version of the same political discussion $(t=14.38$; $d f=1,299 ; p<$. 001). The close-up camera perspectives was significantly more arousing to viewers than the same event shown using a medium camera perspective $(t=28.90 ; d f=1,299 ; p<$. 001). 
Figure 2. Effects of Civility and Camera Perspective on Awareness of Arguments for Own and Opposing Issue Positions (Experiment 2).

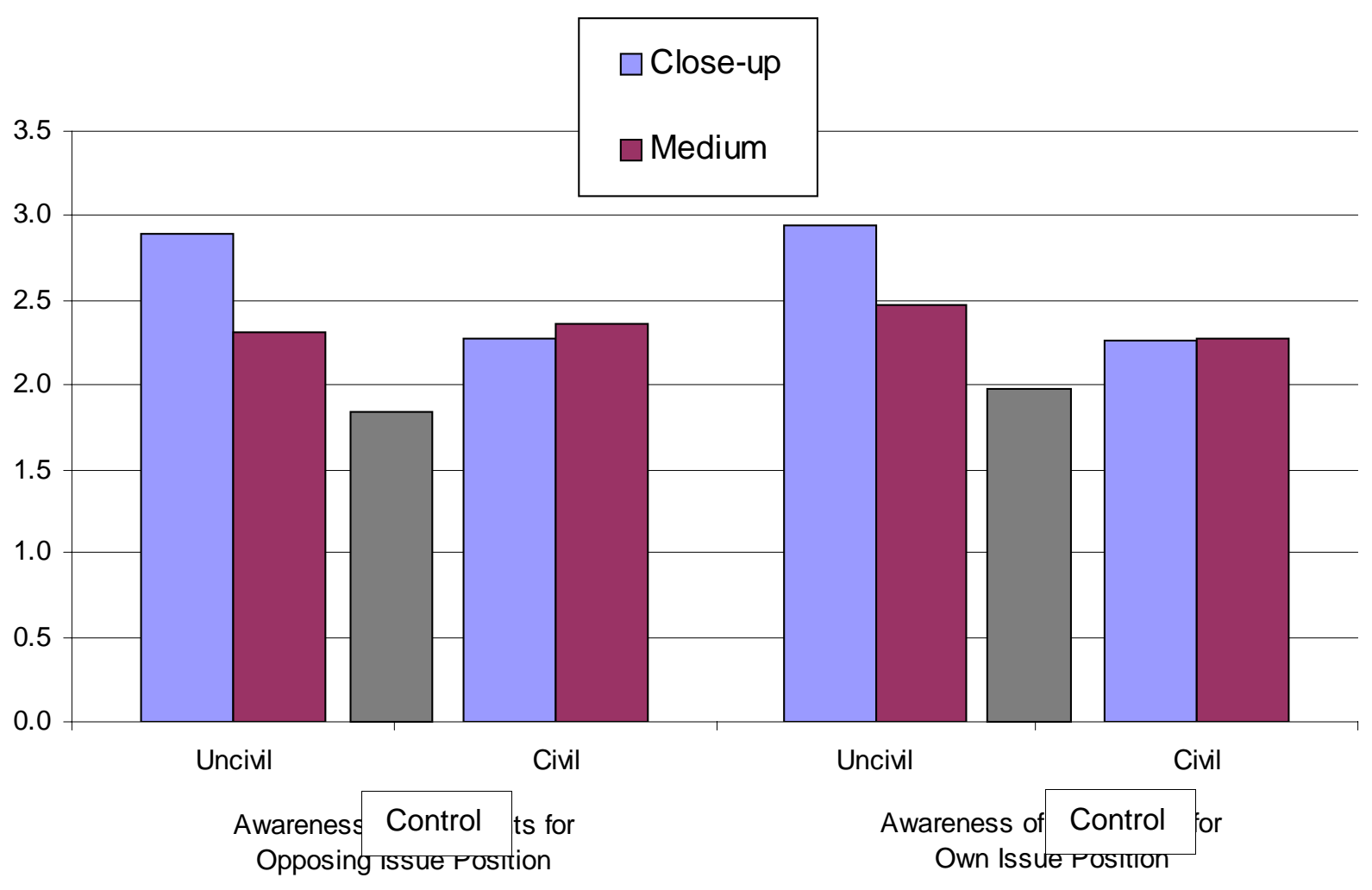

Note: Based on a two by two analysis of variance, the interaction of incivility and close-up camera perspective was significant for awareness of arguments for opposing issue position ( $F=4.36$, $\mathrm{p}<.05)$. For awareness of arguments on one's own side, only incivility significantly enhanced recall $(F=5.13, p<.05)$. All planned contrasts between each of the experimental groups relative to the control condition were significant $(p<.05)$. 
Figure 3. Effects of Civility and Camera Perspective on Difference Between Thermometer Rating of Preferred and Oppositional Candidate (Experiment 2).

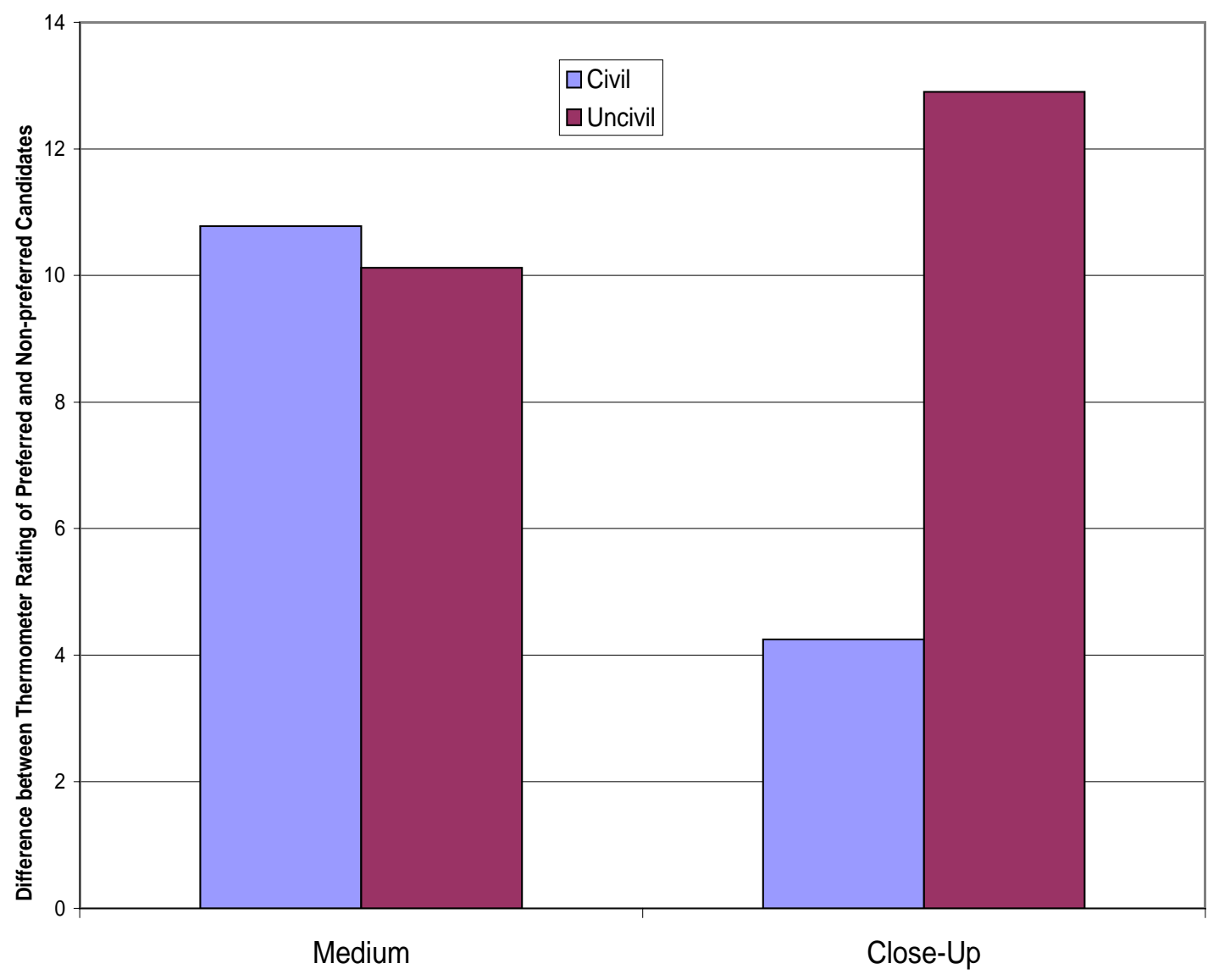

Note: Two factor analysis of variance indicated a significant interaction between civility and camera perspective $(\mathrm{F}=4.84, \mathrm{p}<.05)$. 
Figure 4. Effects of Civility and Camera Perspective on the Perceived Legitimacy of Opposing Arguments (Experiment 2).

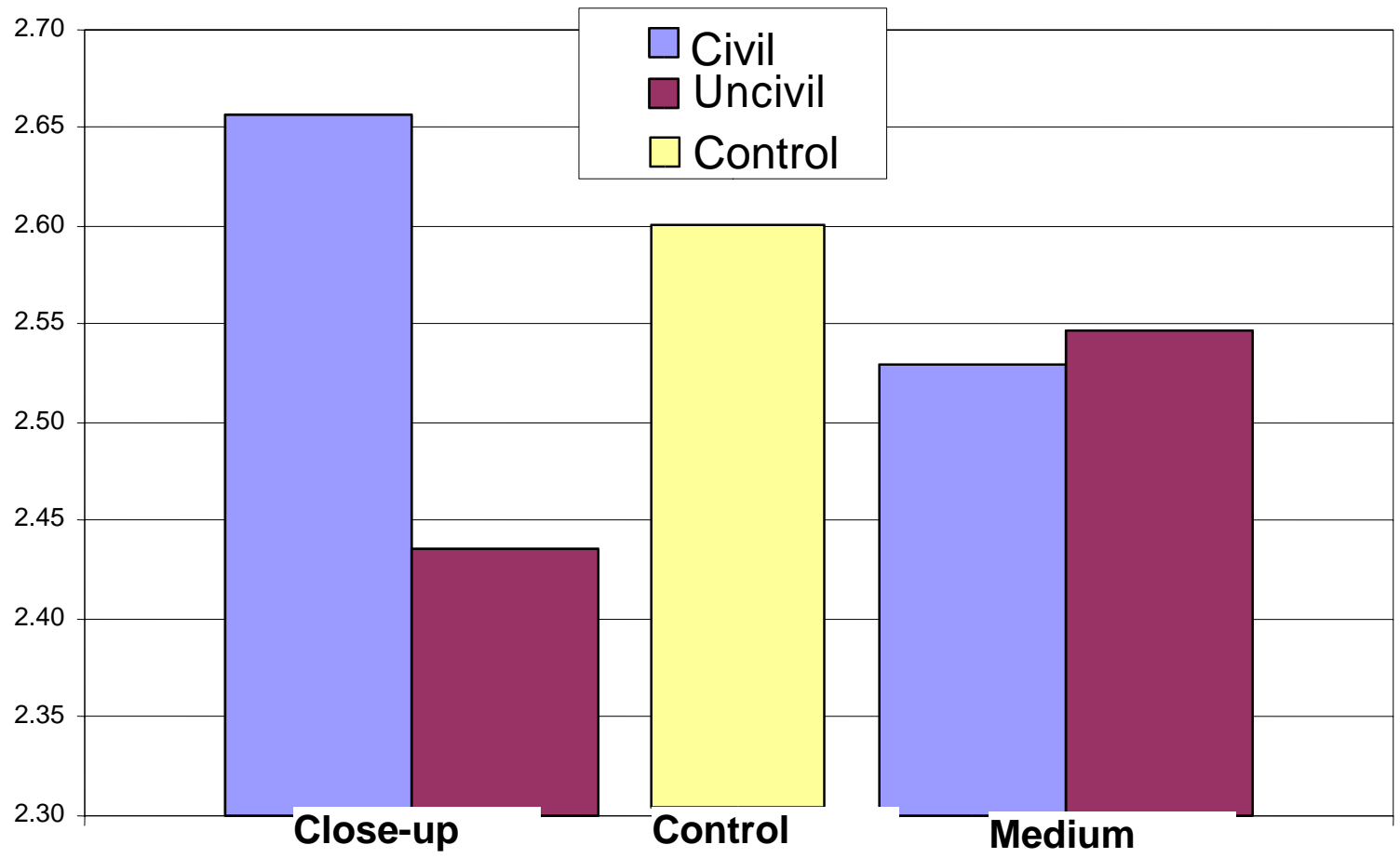

Note: ADD HERE 
Figure 5. Effects of Close-Up/Civility on Thermometer Rating of Preferred and Oppositional Candidate (Experiment 3).

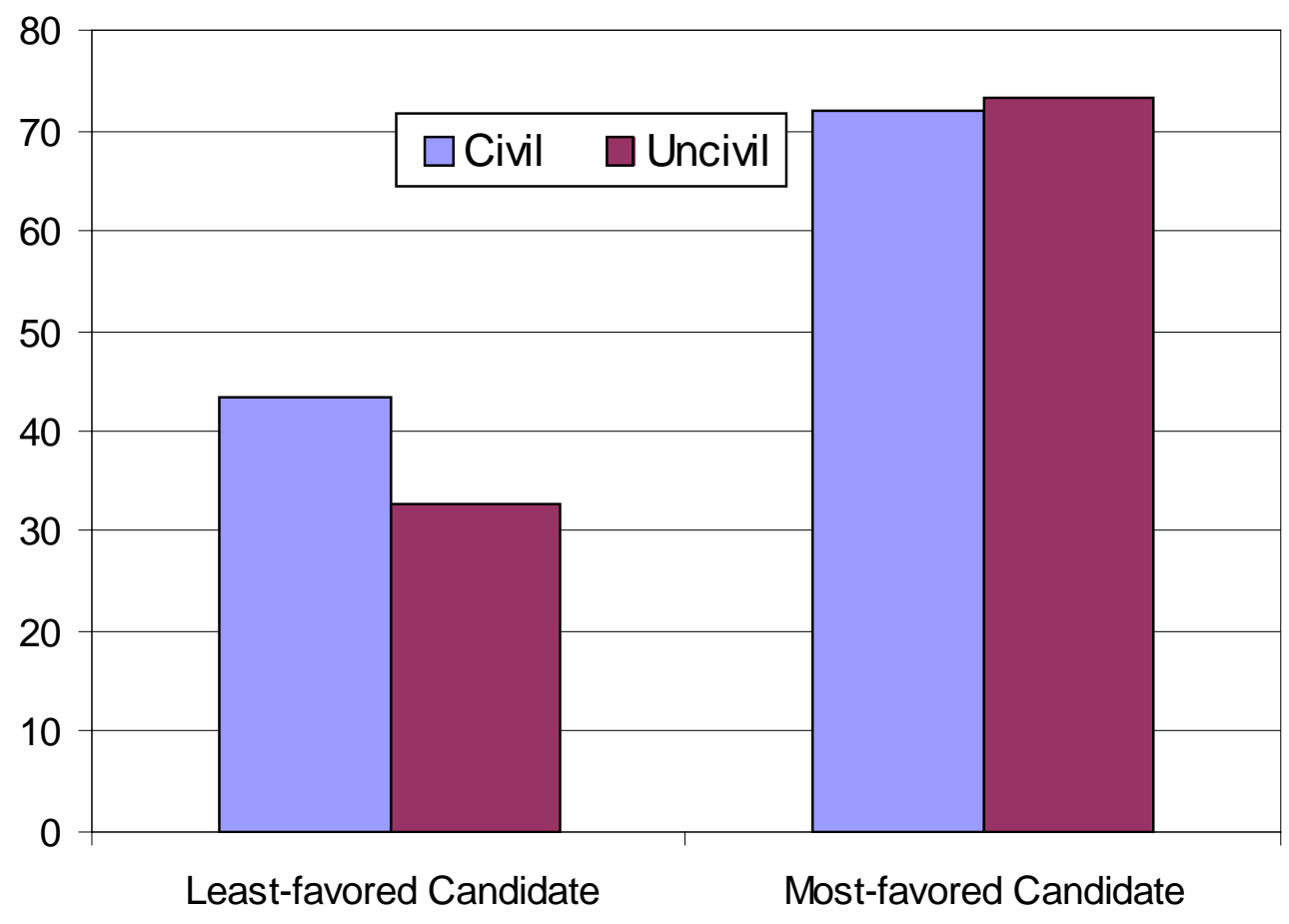

Note: Analysis of variance indicated no significant difference between civil and uncivil conditions for the most-favored candidate $(F=.21, p=.65)$, but a significant difference between conditions for the least-favored candidate $(F=6.17, p<.01)$. The size of the gap between individuals' evaluations of their least- and most-favored candidates also were significant different by condition $(F=5.14, p<.05)$ 
ENDNOTES 
${ }^{1}$ Television cameras were initially so large and heavy that they were entirely stationery, at times with a fixed focal length.

${ }^{2}$ Although their studies focused specifically on the effects of politicians' nonverbal facial displays on public attitudes, they likewise suggest that expressive displays have a direct emotional impact on viewers (see Sullivan and Masters 1987; McHugo et al. 1985). ${ }^{3}$ Extremely high levels of emotional arousal can be overwhelming, and interfere with the encoding of message content (e.g., Loftus and Burns 1982). Thus the relationship between emotional arousal and recall is sometimes curvilinear; recall is low at both the low and the extreme high ends of the arousal spectrum, and highest in the midrange (e.g., Gilligan and Bower 1984). At the highest arousal levels, people may remember the main point, but are unlikely to recall details. However, in the case of politics, the range of potential arousal is likely to be attenuated at the high end, thus making the reactions characteristic of the extremely high levels of arousal unlikely.

${ }^{4}$ The script drew on arguments from interest groups that were for and against eight different issues. All issues had been in the news at the time of the taping of the mock talk show and remained topical at the time of the experiments.

${ }^{5}$ Experiment 1 involved discussions of restrictions on tobacco advertising, taxing internet sales, the repeal of the Glass-Steagall Act affecting financial industries, and whether candidate qualifications should include previous public service experience. Experiment 2 incorporated discussions of restrictions on tobacco advertising, free trade, taxing internet purchases and whether previous public service/political experience is an asset or a liability for a member of Congress. Experiment 3 utilized discussions of NASA funding, insurance coverage for mental health, internet privacy policies, and free trade.

${ }^{6}$ Subjects from temporary employment agencies were compensated at the hourly rate they had previously agreed upon with the agency. Participants from civic groups 
participated as a fund-raising activity for their organizations. Their hourly rates varied based on whether they were coming to campus to participate in strictly this particular study, or a series of studies over several hours.

${ }^{7}$ For each subject, separate time series were created that normalized individual SCL data relative to baseline recordings. This was done because baseline SCL varies considerably across people, and because the major analysis interest is changes in SCL relative to an initial state. Subsequent to within-subject normalization, data were aggregated across subjects and issues to produce separate time series for the four conditions in the experiment (civil/medium shots, civil/close shots, uncivil/medium shots, and uncivil/close shots).

${ }^{8}$ These responses were coded by two independent coders, producing a reliability of .90 for the number of unique arguments generated.

${ }^{9}$ Although many understandings of the concept of legitimacy are possible, the term legitimacy is used here to suggest that a person has heard the other side and granted it some degree of reasonableness as an oppositional viewpoint, despite continued disagreement. If one attributes evil, undesirable motives as the basis of explanation for another's views, or has no comprehension of the opponent's basis for differing views, then one does not perceive the opposition as legitimate. 